University of Louisville

ThinkIR: The University of Louisville's Institutional Repository

\title{
Global-health diplomacy : the social determinants perspective of health approach and the future global policy agenda.
}

\author{
Naseem Ansari \\ University of Louisville
}

Follow this and additional works at: https://ir.library.louisville.edu/honors

Part of the Health and Medical Administration Commons, and the International Public Health Commons

\section{Recommended Citation}

Ansari, Naseem, "Global-health diplomacy : the social determinants perspective of health approach and the future global policy agenda." (2013). College of Arts \& Sciences Senior Honors Theses. Paper 4. http://doi.org/10.18297/honors/4

This Senior Honors Thesis is brought to you for free and open access by the College of Arts \& Sciences at ThinkIR: The University of Louisville's Institutional Repository. It has been accepted for inclusion in College of Arts \& Sciences Senior Honors Theses by an authorized administrator of ThinkIR: The University of Louisville's Institutional Repository. This title appears here courtesy of the author, who has retained all other copyrights. For more information, please contact thinkir@louisville.edu. 


\title{
Global-Health Diplomacy: \\ The Social Determinants Perspective of Health Approach and the Future Global Policy Agenda
}

\author{
By: \\ Naseem Ansari \\ Submitted in partial fulfillment of the requirements \\ for Graduation magna cum laude
}

University of Louisville

March, 2013 


\section{Introduction:}

Within the last two decades, the international community has made significant strides in developing global-health goals. Regional organizations, such as the Organization of American States (OAS) and international organizations, primarily the United Nations, have taken steps to clearly outline the most pressing health-related needs in the developing world, global-health standards, and a variety of policies aimed at encouraging countries to strive to reach basic health thresholds. In addition, a wide array of non-governmental organizations (NGOs), public and private, have stepped forward to provide funding for a broad variety of health initiatives, primarily in the developing world.

Despite these sweeping and far-reaching efforts, global-health policies have had a minimum effect on developing countries. Over the last couple of decades, intellectuals and health-care experts have offered up a variety of mixed assessments of these policies. Nevertheless, perhaps because this is a relatively new subject, very few full development analyses have appeared to examine and assess completely this international health-care approach to addressing the concerns of developing countries. This paper investigates global-health policies and seeks to determine the political determinants that shape their design and implementation and the factors that ultimately contribute to their success or failure in developing countries. Questions to be answered include: How has global-health policy evolved over time? What are past globalhealth policy successes and failures? What does the future of global-health policy hold and what changes should be made to the system in order to ensure the most improvements?

Global-health policy primarily targets a general international audience, and since globalhealth policy are essentially a set of best-practices ideas, they have not developed into a body of international law. Rather, they offer broad one-size-fits-all guidelines to participating countries 
who are seeking assistance in an effort to improve overall health indicators. Many economically weak countries lack both the resources and the knowledge to develop their own set of health policies. Instead, they turn to regional and international organizations for expertise in identifying critical needs, drawing up a budget, applying for international assistance for NGOs and international lending institutions, and setting priorities.

Scholars and health-care experts, however, have broadly criticized the new global-health approach. They argue that broad international policies, highly centralized and bureaucratized, have not been easily applied universally. They contend that a centralized international organization cannot devise a set of policy goals and procedures that can apply to the majority of the world's developing countries. While some scholars and many non-governmental organizations (NGOs) have wholly supported global health-policy goals, others argue that health policies, like all policies, must be locally designed in order to address the particular concerns and needs of the community. From this perspective, health policy cannot actually be "global.” Instead, it must be focused and individualized according to the demands of specifically local ethnic, national, or religious groups. This group of academic skeptics point to problems related to corruption and accountability, drug abuse, and internal ethnic, racial, religious, and culture cleavages. As a recent New York Times article stated, “Sadly, WHO [World Health Organization] has promised much and delivered little.”1

The issue has demanded and entertained increasing levels of media attention to the unfolding threats created by bioterrorism and the question of national health security risks, which have further been the topic of national foreign policy discussions and legislation. International conferences that are devoted to the delivery and mission of maintaining peace and security,

\footnotetext{
${ }^{1}$ New York Times, May 23, 2006 at www.nytimes.com/2006/05/23/opinion.
} 
encouraging friendly relations between states, and resolving international problems of economic, social, cultural or humanitarian nature also generate a great amount of publicity, pushing health policy closer and closer to the forefront of the international political agenda. Accordingly, controversies surrounding the use of public funding for health literacy, disease eradication, and other related health programming measures being instituted in countries worldwide has raised questions about the value and relevance of international health-care policies. Above all, highly centralized global-health governance and international efforts at problem-solving all tend to confront the same obstacles: lack of coordination among contributing and executing partners, fragmentation and duplication in a system that both fails to delineate procedures measuring accountability and produce reliable data needed for the analysis of outcomes and success, and a notable contrast in the ratio of capital resource allocation versus human resource allocation during implementation and delivery of health initiatives. Some scholars have asked: Is the "global" approach the best, most effective approach? The global approach is increasingly becoming the approach of choice both in the United States and around the world and is widely attributed as the reason for both health successes, such as the small pox eradication campaign, and notorious failures, such as the HIV/AIDS health programming in the region of Sub-Saharan Africa. Yet, the question to be answered now is whether or not states are investing considerable time into a discipline whose very framework is fundamentally flawed.

The first part of this paper will discuss broadly the evolution of past global-health diplomacy and policy. I introduce the history of global-health diplomacy as it has evolved from its beginnings to modern times. Then, I critique the Millennium Development Goals as the primary policy goal and overarching mission of global health agenda in the 21st century by examining their specific achievements and relaying significant criticisms. Next, I detail the 
progress being made in the development of a more comprehensive, holistic global health model, which is now known as the social determinants of health perspective.

The second part of this paper will analyze the development and impact of three current sociopolitical health frameworks on the international level: health as a matter of security, health in the context of development, and health as a human right. These three frameworks are the ones most frequently utilized to both collect funding for global-health programs and to explain the basis of foreign-policy choices. Each framework has its own strengths and weaknesses and may serve to predict the likelihood of success of the new social determinants of health perspective on the future global-health policy agenda.

Finally, I argue that the conflicts created by the different global-health sociopolitical frameworks and the lack of accountability and legitimacy imposed by an unclear structural hierarchy in global health governance could potentially impede the success of the social determinants of health perspective and ultimately prevent long-lasting improvement. Moreover, I assert that progress is dependent on more participation from communities and accountability from the recipients of aid. I also assert that public sector actors should look to the evaluation standards and performance models of successful private sector organizations such as the Global Fund to Fight HIV/AIDS, Tuberculosis, and Malaria and the Bill and Melinda Gates Foundation to formulate mechanisms for generating an environment of increased accountability and incentivized resource allocation disbursal. Finally, I assert the need for a different organization to process, evaluate, and analyze the data generated by public sector organizations because of the inherent conflict that arises when the same entity designs, implements, and measures the progress of its own creation.

\section{Part 1: A Brief History of Global-Health Diplomacy}




\section{Beginnings: The Necessity of a Global System of Governance}

Global-health diplomacy traces roots to the regional discussions that occurred during the International Sanitary Conference in 1851 among European states as they attempted to resolve a means of cooperation to handle cholera, plague, and yellow-fever epidemics. Debates ensued that addressed the need for "international regimes capable of responding to global threats of public health." ${ }^{2}$ The states participating agreed to continue convening the International Sanitary Conference and utilize the forum as a venue for collaboration in specific health initiatives and the resolution of critical health obstacles.

These international conferences and regional meetings became the precursors to the modern International Health Regulations of 2005, "a multilateral agreement that outlines countries' obligations and responsibilities for detecting, reporting, and responding to health events of international concern such as disease epidemics and pandemics." ${ }^{3}$ The evolution of scientific theory, specifically in relation to the work by Pasteur and Koch on germ theory in the 1860s, helped to encourage international cooperation as it contributed to the understanding of the transmission of disease and provided a multitude of supporting evidence for the environmental and social factors that influenced health. Pasteur and Koch explained that specific factors, such as unclean water sources and overcrowding in urban areas, promoted the spread of epidemics such as cholera and yellow-fever.

Movement along the arc of theory development and acceptance of the need for international governance in the realm of health and politics was driven by an ever-increasing level of globalization and its impacts. Ronald Labonte, in his article on the connections between

\footnotetext{
${ }^{2}$ Fidler, David, "The globalization of public health: the first 100 years of international health diplomacy," The World Health Organization, 2001 at http://cdrwww.who.int/bulletin/archives/79(9)842.pdf.

${ }^{3}$ The Henry J. Kaiser Family Foundation, "Raising the profile in the U.S. Global Health Response: A Backgrounder on Global Health Diplomacy," September 1, 2012 at http://www.kff.org/globalhealth/upload/8360.pdf.
} 
globalization, health, and development, defined globalization as a network of "processes by which nations, businesses, and people become more connected and interdependent via increased economic integration and communication exchange, cultural diffusion, and travel." 4

Colonial expansion, the fervor that revolutionized missionary efforts, the socioeconomic and political reflections of two world wars among leading intellectual centers of the time, the necessity for regulation in the international trade of narcotics such as opium and alcohol, and imperial countries fostering post-colonial guilt, are all factors that shaped the founding of a number of international health institutions. At the 1903 International Sanitary Conference, European representatives supported the need for a permanent international health bureau. Nevertheless, the US had already created their own International Sanitary Bureau in 1902, which was later renamed the Pan American Sanitary Bureau. The result of a 1907 meeting in Rome was the establishment in Paris of an Office International d'Hygiène Publique (OHIP), which boasted a permanent, full-time secretariat and a committee of senior public health officials from participating governments. Other international ventures included the International Opium Convention in 1912, which led to the 1925 Agreement Concerning the Manufacture of, Internal Trade In, and Use of Prepared Opium. This agreement sought to both restrict and guide economic interests and garner support for the marginalized populations in Africa and the Native American groups in the Americas. The International Labor Organization of 1919, which mandated regulation of occupational health-safety standards, also profoundly impacted the development of global-health policy. Perhaps the most notable of these ventures was the design and founding of the League of Nations Health Organization in 1924. The League of Nations specifically acknowledged its "endeavor to take steps in matters of international concern for the

\footnotetext{
${ }^{4}$ Labonte, Ronald and Renee Torgerson, "Interrogating globalization, health, and development: towards a comprehensive framework for research, policy, and political action," Critical Public Health, 15(2): 2005
} 
prevention and control of disease". ${ }^{5}$ Significantly, controversy and fragmentation in global health attribute their beginnings to the uncertainty and divergence surrounding the incorporation of the OHIP within the administrative jurisdiction of the League. The United States, a prominent member of the OHIP, but not of the League, undermined the possibility of this inclusion and international cohesion. Therefore, the "years between the two World Wars, two independent international health organizations co-existed in Europe - the OIHP and the Health Organization of the League of Nations". ${ }^{5}$ The OHIP, the League of Nations, and the Pan-American Sanitary Bureau collectively interacted to develop and execute global-health policy during this time. Simultaneously, private organizations such as the Rockefeller Organization and the International Union Against Tuberculosis improved global-health policy and strengthened international cooperation in designing political, economic, and social policy. World Health Organization: The Administration of Global-Health Policy

The ultimate apex of global-health diplomacy in the twentieth century was the establishment of the World Health Organization (WHO) in 1948 as a part of the United Nations (UN), which formed in 1944 in the post-World War II era. Brazilian and Chinese UN conference representatives proposed that an international health organization be founded; consequently, a conference to frame this new organization's constitution was summoned as a result of instructions given the UN Secretary General by the Economic and Social Council. Conference members revised and adopted a constitution for a WHO, which was endorsed by representatives of $51 \mathrm{UN}$ member states and ten additional states. WHO would be a specialized organization of the United Nations as dictated by both the preamble and Article 69 of the WHO constitution. Because of the necessary member signatures needed for the ratification of the constitution, WHO

\footnotetext{
${ }^{5}$ United Nations History http://www.who.int/global_health_histories/background/en/index.html
} 
did not officially become an operating entity until April 1948. During the interim years that unfolded during the delayed ratification of the constitution, the Health Division of the UN Relief and Rehabilitation Administration (UNRRA) and the Interim Commission of WHO assumed the temporary responsibility for the operative duties of the organization. This interim commission also absorbed responsibility for the international sanitary conventions and for international epidemiological reporting data, which was collected through the management of the International Classification of Disease and similar programs. ${ }^{5}$

WHO became the focal point for global diplomatic activity regarding health at the international level throughout the rest of the twentieth century and into the twenty first century. In the course of the creation of conventions such as the World Health Assembly (WHA), in which international health discussions were held and policy negotiated annually by representatives of all member states, WHO maintained a forum that addressed international health concerns, gathered support in the form of monetary donations, and encouraged promises of advocacy within individual states and groups of states. These new initiatives, brought on through consensus-building and international compromise, marked a significant achievement in the history of global-health diplomacy.

The role of global-health evolved increasingly as technology developed and medical discoveries enabled WHO and its counterparts to make considerable achievements in the eradication of infectious diseases. The Global Yaws Program, once fully operational, used penicillin injections to cure inflicted persons of yaws, a crippling, disfiguring disease that affected millions; the program succeeded in reducing the global prevalence of the disease by more than 95 percent between 1952 and 1964, examining more than 300 million people in 46 countries. Between 1967 and 1979, WHO's campaign to fight smallpox resulted in the 
eradication of the disease, an accomplishment that remains one of the organization's proudest achievements. ${ }^{6}$ As Dybul, Piot, and Frenk note in their policy review on global-health governance, unprecedented growth of global-health was "part of a broader conceptual framework that created core principles for the use of resources in a new era of development." ${ }^{7}$ This new wave of ideas and the transformation of perspectives was reinforced by the Declaration of Alma Ata, a product of the 1978 International Conference on Primary Health Care in Kazakhstan, expressing "the need for urgent action by all governments, all health and development workers, and the world community to protect and promote the health of all the people of the world." ${ }^{8}$ Alma Ata is regarded as the first international acknowledgement of the importance of primary health-care and indicated a significant change in the history of global-health diplomacy, as health became not only a critical focus of policy agendas but also a recognized right of all people.

Largely, leaders and academics began to recognize that health-policy measures could be institutionalized as a means to mediate ethnic conflict and resolve political turmoil. A program known as "Health as a Bridge to Peace” to support such causes quickly surfaced on the WHO agenda to serve these bilateral and multilateral purposes. ${ }^{9}$ Health continued to be an effective tool for diplomatic engagement through the 1980s and 1990s, "when a number of health programs and so called "vaccine diplomacy' efforts were credited with precipitating cease-fires and aiding political negotiations in conflict zones such as Sierra Leone, Sudan, El Salvador, and Bosnia." ${ }^{10}$

\footnotetext{
${ }^{6}$ World Health Organization Brochure http://www.who.int/about/brochure_en.pdf

${ }^{7}$ Dybul, Mark, Peter Piot, and Julio Frenk, "Reshaping Global Health," Policy Review, 173: 2012

${ }^{8}$ WHO Declaration of Alma Ata http://www.who.int/publications/almaata_declaration_en.pdf

${ }^{9}$ World Health Organization, "Health as a Bridge to Peace (HBP)," http://www.who.int/hac/techguidance/hbp/en/.

${ }^{10}$ Hotez, "Vaccine Diplomacy," Foreign Policy http://www.foreignpolicy.com/articles/2001/05/01/vaccine_diplomacy.
} 
The UN Security Council declaration of HIV/AIDS as a global security threat and simultaneous creation of a new departmental agency, UNAIDS, in 1996 represented the advanced, multi-faceted analytical approach needed to both comprehend and evaluate globalhealth. UNAIDS, an entire new branch that would both report to WHO and to the UN Security Council, would conduct the policy discussions and proceedings generated in an attempt to mitigate the effects of the disease and devise programmatic proposals to handle the far-reaching scope of the issue of health as a security risk. International alarm and fear of the ramifications of HIV/AIDS spread rapidly; this marked the first time any disease had been singled out as both a health and security concern. ${ }^{3}$

\section{Defining International Responsibility in Health}

The combination of rising international health security concerns and increasingly published academic literature involving the economic, social, security, and human rights elements associated with the concept of 'health' cultivated a global policy environment that encouraged international commitment and cooperation and invoked connotations of both obligation and responsibility regarding the provision of quality health services to all people, among populations around the world. The Monterrey Consensus, reached during a meeting of the International Conference on Financing for Development in Monterrey, Mexico in March 2002, stipulated "the need for developing countries to take responsibility for their own poverty reductions and the necessity for rich nations to support this endeavor with more open trade and increased financial aid." ${ }^{11}$ The UN reported that the Monterrey Consensus, a collective body consisting of more than 50 heads of state along with representatives of the World Bank, the International Monetary Fund (IMF), and the World Trade Organization (WTO), was a "landmark

\footnotetext{
${ }^{11}$ World Bank, "What is the Monterrey Consensus?" http://siteresources.worldbank.org/KFDLP/Resources/4611971122319506554/What_is_the_Monterrey_Consensus.pdf
} 
framework for global development partnership in which developed and developing countries" are assigned responsibility in alleviating global poverty. ${ }^{12}$ This consensus was later refined by the High Level Forum on Harmonization in Rome in 2003 and by the Paris Declaration on Aid Effectiveness in 2005. The forum in Rome, convened by the Organization for Economic Cooperation and Development (OECD), resulted in a pact stating that donor agencies and programs would attempt to integrate their objectives and missions within each country as well as with other donor agencies operating in the country in question, to further the likelihoods that the socioeconomic country climate was receptive to aid and that donor agencies were neither wasting funding through the duplication of efforts nor implementing inefficient programs. The Paris Declaration advocated five principles to improve aid effectiveness: (1) ownership with respect to the understanding and commitment of partner countries, the recipients of aid and donors of aid, (2) alignment of donor's mission and goals with the specific government and development programs in place in each country, (3) harmonization of implementation and delivery of programming and funding, (4) better management and efficiency to create direct results, and (5) mutual accountability between partner countries of initiative outcomes. ${ }^{13}$ Fundamentally, the Paris Declaration developed a clear and inclusive best-practices model for countries seeking to enter partnerships intended to further global-health objectives, incorporating the resolutions reached in Monterrey and in Rome. The Paris Declaration was reported by WHO to have the "potential to alleviate the risk of fragmentation of health" and would "lead inevitably

\footnotetext{
${ }^{12}$ United Nations, "Investing in Development: A Practical Plan to Achieve the Millennium Development Goals," www.unmillenniumproject.org/reports/fullreport.htm

${ }^{13}$ Organization for Economic Cooperation and Development, "Paris Declaration on Aid Effectiveness and the Accra Agenda for Action," http://www.oecd.org/development/effectiveness/34428351.pdf
} 
to a stronger consideration of the systemic aspects of health-care," providing a framework that might motivate stakeholders from all parties to invest in the strengthening of health systems. ${ }^{14}$

Further evidence of the growing relationship between diplomacy and health and of the international attention it receives is apparent in the joint declaration signed in 2007 by a diverse set of countries including Brazil, France, Indonesia, Norway, Senegal, South Africa, and Thailand. This declaration, now known as the Oslo Ministerial Declaration, labeled global health as a "pressing foreign policy issue of our time,” and listed health as a “defining lens” for shaping foreign policy. ${ }^{15}$ The Accra Agenda for Action of 2008 further expanded on and reinforced the necessary and vital commitment of states to the Paris Declaration on Aid Effectiveness. The Accra Agenda for Action, along with the Paris Declaration and the Oslo Ministerial Declaration are all examples of states collectively recognizing the need for change, for improved communication between donor and recipient parties, and for strengthened systems of healthcare through data collection, causal analysis, and human capital. No system of regulation or governance, however, mandates that states uphold their commitment and support of these international statements. Understanding the mechanisms of change in global-health diplomacy is critical to future success, but without any firm structural directives, the ideology behind these premier documents faces tremendous difficulty in becoming reality.

\section{Global-Health Policy Implementation: United Nations Millennium Development Goals}

The Millennium Development Goals, the written result of the 2000 United Nations Millennium Summit, predominates as the central doctrine of global aid and policy efforts aimed

\footnotetext{
${ }^{14}$ Nicolaus Loren, "Effectiveness of Global Health Partnerships: Will the past repeat itself? World Health Organization, http://www.who.int/bulletin/volumes/85/7/06-033597/en/

${ }^{15}$ Labonté, Ronald and Gagnon , "Framing Health and Foreign Policy: Lessons for Global Health Diplomacy," Globalization and Health, 6:(14) 2010, http://www.globalizationandhealth.com/content/6/1/14
} 
at reducing global poverty. A press release published by the UN secretariat in the days following

the Summit stated the document affirmed a "resolve action to strengthen peace, development,

Table 1: Millennium Development Goals.

1. Eradicate extreme poverty and hunger.

Target 1. Halve, between 1990 and 2015, the proportion of people whose income is less than \$1 a day

Target 2. Halve, between 1990 and 2015, the proportion of people who suffer from hunger

\section{Achieve universal primary education.}

Target 3. Ensure that, by 2015, children everywhere, boys and girls alike, will be able to complete a full course of primary schooling

\section{Promote gender equality and empower women.}

Target 4. Eliminate gender disparity in primary and secondary education, preferably by 2005, and in all levels of education no later than 2015

\section{Reduce child mortality.}

Target 5. Reduce by two-thirds, between 1990 and 2015, the under-five mortality rate

\section{Improve maternal health.}

Target 6. Reduce by three-quarters, between 1990 and 2015, the maternal mortality ratio

\section{Combat HIV/AIDS, malaria, and other diseases.}

Target 7. Have halted by 2015 and begun to reverse the spread of HIV/AIDS

Target 8. Have halted by 2015 and begun to reverse the incidence of malaria and other major diseases

\section{Ensure environmental sustainability.}

Target 9. Integrate the principles of sustainable development into country policies and programs and reverse the loss of environmental resources

Target 10. Halve, by 2015, the proportion of people without sustainable access to safe drinking water and basic sanitation

Target 11. Have achieved by 2020 a significant improvement in the lives of at least 100 million slum dwellers

\section{Develop a global partnership for development.}

Target 12. Develop further an open, rule-based, predictable, nondiscriminatory trading and financial system (includes a commitment to good governance, development, and poverty reduction both nationally and internationally)

Target 13. Address the special needs of the Least Developed Countries

Target 14. Address the special needs of landlocked developing countries and small island developing states Target 15. Deal comprehensively with the debt problems of developing countries through national and international measures in order to make debt sustainable in the long term

Target 16. In cooperation with developing countries, develop and implement strategies for decent and productive work for youth

Target 17. In cooperation with pharmaceutical companies, provide access to affordable essential drugs in developing countries

Target 18. In cooperation with the private sector, make available the benefits of new technologies, especially information and communications technology 
human rights; to improve [the] UN's ability to act on behalf of humanity's priorities" among the "largest-ever gathering of world leaders." The document further stated the "values, principles, and objectives for the international agenda for the twenty-first century." ${ }^{16}$ The Millennium Development Goals (MDGs) statement consists of eight goals and eighteen targets with the collective deadline of 2015. Three of the eight goals directly correspond to health although it has been since noted that health remains an underlying contributor to the achievement of all eight goals. $^{17}$

- Goal 4: Reduce child mortality.

- Goal 5: Improve maternal health.

- Goal 6: Combat HIV/AIDS, malaria, and other diseases

Forty-eight specific indicators have been identified as the means of assessing the success of each target. Two indicators listed in conjunction with Goal 5 include the maternal mortality ratio and Table 2: MDG Indicators in 2004 for Selected Countries. ${ }^{18}$

\begin{tabular}{|c|c|c|c|c|c|c|}
\hline Country & USA & Mexico & Thailand & Botswana & India & Sierra Leone \\
\hline $\begin{array}{l}\text { Under } 5 \text { mortality rate (per } 1000 \text { live } \\
\text { births) }\end{array}$ & 9 & 29 & 31 & 93 & 96 & 316 \\
\hline $\begin{array}{l}\text { 1-year-olds immunized against } \\
\text { measles }\end{array}$ & $91 \%$ & $95 \%$ & $94 \%$ & $90 \%$ & $56 \%$ & $53 \%$ \\
\hline $\begin{array}{l}\text { Maternal mortality ratio (per 100,000 } \\
\text { live births) }\end{array}$ & 14 & 83 & 44 & 100 & 540 & 2000 \\
\hline $\begin{array}{l}\text { Births attended by skilled health } \\
\text { professionals }\end{array}$ & $99 \%$ & $85.7 \%$ & $85 \%$ & $98.5 \%$ & $42.3 \%$ & $41.7 \%$ \\
\hline $\begin{array}{l}\text { HIV prevalence among } 15 \text { to } 49 \text { year } \\
\text { olds }\end{array}$ & $0.6 \%$ & $0.2 \%$ & $1.9 \%$ & $37.5 \%$ & $0.8 \%$ & $2.0 \%$ \\
\hline $\begin{array}{l}\text { Malaria related mortality rates (per } \\
100,000 \text { ) }\end{array}$ & 0 & 0 & 7 & 8 & 3 & 321 \\
\hline $\begin{array}{l}\text { Tuberculosis mortality rate (per } \\
\text { 100,000) }\end{array}$ & 4 & 49 & 225 & 288 & 431 & 573 \\
\hline $\begin{array}{l}\text { Sustainable access to an improved } \\
\text { water source (rural) }\end{array}$ & $100 \%$ & $95 \%$ & $95 \%$ & $100 \%$ & $95 \%$ & $75 \%$ \\
\hline Access to improved sanitation (rural) & $100 \%$ & $34 \%$ & $96 \%$ & $43 \%$ & $15 \%$ & $53 \%$ \\
\hline
\end{tabular}

\footnotetext{
${ }^{16}$ United Nations Press Release http://www.un.org/News/Press/docs/2000/20000908.ga9758.doc.html

${ }^{17}$ Jacobsen, Dr. Kathryn H. Introduction to Global Health, (Boston: Jones and Bartlett Publishers, 2008 ): 282.

${ }^{18}$ World Health Report 2004, http://www.who.int/whr/2004/en/.
} 
the proportion of births attended by skilled health professionals. A sample collection in Table 2 displays an aggregation of several health-related MDGs indicators for selected countries.

Each year, the WHO compiles and analyzes data received from numerous organizations monitoring health including the United Nations International Telecommunication Union, (ITU), the United Nations Department of Economic and Social Affairs (UNDESA), the United Nations Educational, Scientific and Cultural Organization (UNESCO), the United Nations Children's Fund (UNICEF) and the World Bank. The intended goal of these annual reports is to evaluate and measure the progress made toward each goal with respect to individual and collective targets. To many, the notion of progress in global-health is either deemed justified or baseless depending on the statistics reported by the UN, as they present the most comprehensive measurements on global health standards and performance to date. Because of their consistently published and quantifiable measurements, the MDGs have attracted much international attention and polarized the global health agenda toward extremes: the focus on few health problems at the expense of all others.

Overall, the MDGs have established a precedent of vertically designed programming that streamlines its focus on the improvement of one particular issue. HIV/AIDS offers one example. In 2003, a total of U.S. \$4.2 billion was exhausted on HIV/AIDS assistance at international and national levels, making it one of the most significant health-programming expenditures of the year. ${ }^{19}$ Through a 2008 WHO report, however, revealed that the top 10 causes of death in the world are largely not a result of HIV/AIDS. This report is summarized in Table 3. These statistics do not justify so much funding to a single health problem.

\footnotetext{
${ }^{19}$ Doyle, Joseph S. "An International Public Health Crisis: Can Global Institutions Respond Effectively to HIV/AIDS?" Australian Journal of International Affairs, 60(3): 2006.
} 
Non-communicable diseases as a whole encompass more than 50 percent of the causes for death, while HIV/AIDS is charged with only 3.1 percent. The funding allotted by WHO toward non-communicable diseases barely surpasses 12 percent of their budget as of 2008, while the funding allotted toward the prevention and treatment of HIV/AIDS has risen rapidly and continues to rise still. ${ }^{25}$ Furthermore, HIV/AIDS funding amounts from 1998 to 2003 rose from 7.2 percent to 23.8 percent, tripling in only half a decade. ${ }^{20}$

Table 3. World Health Organization: Leading Causes of Death in $2008 .^{21}$

\begin{tabular}{|l||l||l||}
\hline \multicolumn{1}{|c|}{ World } & Deaths in millions & $\%$ of deaths \\
\hline Ischemic heart disease & 7.25 & $12.8 \%$ \\
\hline \hline Stroke and other cerebrovascular disease & 6.15 & $10.8 \%$ \\
\hline \hline Lower respiratory infections & 3.46 & $6.1 \%$ \\
\hline \hline Chronic obstructive pulmonary disease & 3.28 & $5.8 \%$ \\
\hline Diarrheal diseases & 2.46 & $4.3 \%$ \\
\hline \hline HIV/AIDS & 1.78 & $3.1 \%$ \\
\hline Trachea, bronchus, lung cancers & 1.39 & $2.4 \%$ \\
\hline \hline Tuberculosis & 1.34 & $2.4 \%$ \\
\hline \hline Diabetes mellitus & 1.26 & $2.2 \%$ \\
\hline \hline Road traffic accidents & 1.21 & $2.1 \%$ \\
\hline \hline
\end{tabular}

The U.S. budgets show a profound shift in funding priorities as well, as the percentage of overall health expenditures devoted to HIV/AIDS has risen from 9.4 percent to 43.1 percent, far surpassing all other categories. ${ }^{22}$ After factoring in the funding allotted by the Global Fund, PEPFAR (The President's Emergency Plan for AIDS Relief), and the Bill and Melinda Gates Foundation, the ratios between funding on other initiatives versus that of HIV/AIDS become

\footnotetext{
${ }^{20}$ Organization for Economic Cooperation and Development International Development Statistics 2005, Paris: 2005.

${ }^{21}$ World Health Organization, "Top 10 Causes of Death" http://www.who.int/mediacentre/factsheets/fs310/en/index.html.

22 Jeremy Shiffman, "HIV/AIDS and the Rest of the Global Health Agenda," World Health Organization, http://www.who.int/bulletin/volumes/84/12/06-036681.pdf.
} 
more disproportionate. The fragmentation of the global health system is a great contributor to the general likelihood of these effects: each individual organization becomes highly focused on the delivery and relief of one issue and lead to a overwhelmingly biased system.

Moreover, the focus on the MDGs, largely as a result of the indicators chosen for evaluation, has been primarily on disease immunization and eradication efforts, and other initiatives that quickly calculate persons reached. Consequently, the delivery of funding to initiatives that attempt to mediate social stigma, educate people about the importance of safe sexual practices or the significance of proper waste disposal--programs that will not facilitate direct and immediate data--is fewer and farther in between. Margaret Chan, the Director of the WHO acknowledged in her address to a meeting of the European Union that the MDG goals and targets "operate as a corrective strategy." 23 They are implemented as reactionary measures to mediate the problems that accompany globalization and uneven development. Relying on a system that operates reactively instead of proactively is neither cost-effective nor efficient for preserving long-term goals.

Progress has been reported in specific initiatives. Overall mortality rates, for example, are expected to be on the decline for all "main" infectious diseases, which primarily alludes to malaria, tuberculosis, and HIV/AIDS. Global deaths resulting from HIV/AIDS are expected decline from 2.2 million in 2008 to $1-2$ million in 2030, given that the current antiviral drug coverage continues. ${ }^{24}$ In addition, the mortality of children less than five years of age has decreased substantially from an estimated 13.5 million in 1980 to near 9.7 million in 2005 .

By 2015, child mortality has been projected to have declined overall by 27 percent worldwide. This decline is a significant achievement, yet it does not meet the 67 percent target

\footnotetext{
${ }^{23}$ Margaret Chan, "The Quest for a Coherent Global Health Policy," World Health Organization, Brussels, 2010. http://www.who.int/dg/speeches/2010/globalhealth_conf_201006011/en/index.html.

${ }^{24}$ UNAIDS, "AIDS Epidemic Update: December 2007" World Health Organization, Geneva: 2007.
} 
mandated in MDG 4 (See Table 1). ${ }^{25}$ Moreover, UN 2012 Millennium Development Report declared that the world is currently "on track to achieve the target of halting and beginning to reverse the spread of tuberculosis." Recent statistics suggest that the 1990 worldwide death rate from the disease will have halved by 2015.

The 2012 Report also states that since 2000 the estimated frequency of malaria decreased by 17 percent. Malaria-specific mortality rates have been reduced by 25 percent and reported malaria cases have "decreased by more than 50 percent between 2000 and 2010 in 43 of the 99 countries with ongoing malaria transmission." ${ }^{26}$ These statistics prove promising to the mission of the MDGs, but an absolute halt and reversal in disease incidence remains unlikely. The MDGs have been criticized profusely for the wide-sweeping language that fills the texts; the texts are not only ambitious, they are ambiguous, leaving a series of impressive connotations that are highly unrealistic. Because the terms are aggregate in nature, improvements in health outcomes that would appear to be adequately meeting MDG indicators in national level surveys reflects only overall change in the population's health standards. For instance, a country may theoretically achieve MDG targets when high-income and middle-income populations improve sufficiently. Yet, low-income and impoverished groups that the MDGs were designed to most impact, see no improvements. In this scenario, a country is actually widening the inequalities seen between high and low income groups.

More comprehensive goals such as MDG 4, MDG 5, and MDG 7 have struggled to attain sizeable gains as evidenced by their indicators. A BBC News article testified in 2011 that researchers indicated that "just nine of 137 developing countries will achieve ambitious targets to

\footnotetext{
${ }^{25}$ Beaglehole, Roger and Ruth Bonita, "Global Public Health: A Scorecard," Lancet, 372:2008.

${ }^{26}$ United Nations 2012 Millennium Development Goals Report. http://mdgs.un.org/unsd/mdg/Resources/Static/Products/Progress2012/English2012.pdf
} 
improve the health of women and children" [MDG 4 and MDG 5]. ${ }^{27}$ This small success rate is evidence of the need for a more complex, nuanced, multi-tiered, country-specific, and needspecific approach to health problems.

On a more positive note, the UN recently reported that MDG 1, the eradication of extreme poverty had been achieved already, along with the target [Target 10, Table 1] of halving the proportion of people without access to an improved water source. Those with sustainable access to safer drinking water has grown from 76 percent in 1990 to 89 percent in 2010. This means that over the course of twenty years, between the years of 1990 and 2010, more than two billion people found access to improved drinking water sources. ${ }^{26}$

Yet, despite the promises these achievements reveal, critics continue to question the accuracy of measurements employed and the likelihood of duplication of subjects in reports through multiple donor databases. Most of the data for the MDGs are collected via household surveys, which consist of door-to-door interviews in most cases. When three or more different donor agencies are operating within the same country, cities, and neighborhoods, the probability that many households are counted twice is high.

Regardless of the specific successes or failures of the MDGs, the true significance lies in the immediacy of 2015, the post-MDG era. As these eight overarching goals have dominated the global-health agenda for the past decade and a half, scholars have acknowledged that the world must create new and better objectives and accommodate the changing nature of health. The MDGs have revealed the vast improvements that can be accomplished through vertically implemented directives, have taught the importance of worldwide investment in health, and have alluded to the global health issues of the future, issues that demand a more multifaceted approach.

\footnotetext{
${ }^{27}$ Dreaper, Jane, "Millennium Development Goals on health 'will not be met" BBC News. September 19, 2011
} 


\section{A New Agenda for Global Health Policy}

The 2012 World Health Report, published by the World Bank, and even lessons taken from the preliminary results of the Millennium Development Goals all point to a new globalhealth-policy agenda that is more focused on the social determinants of health. The premise of the social determinants of health perspective began from the idea that "systematic differences in health outcomes exist between groups defined by income, education, occupation, race/ethnicity, gender, and geographical location of residence within countries" and between countries. ${ }^{31}$ Research has overwhelmingly demonstrated that health inequity is influenced by a nation's wealth, economic outlook, and sociopolitical environment, further indicating that this inequity cannot be solely based on biological determinants and is therefore avoidable.

Evidence supporting the social determinants of health is plentiful with regard to many health issues, including child mortality and the need for increased aid levels for reproductive health care and family planning. Figure 1 measures the incidence of mortality between 2000 and 2010 in children under five years of age from the poorest 20 percent of households as compared to those from the richest 20 percent of households. Children born into poverty are almost twice as likely to die before reaching the age of five than their counterparts from wealthier households. For this graph, data was collected from 73 developing countries and accounts for 71 percent of the total births in developing countries in 2010. The data points to a clear relationship between wealth and child health and health in general.

Figure 2 illustrates the current need for aid for reproductive health and family planning. The education services needed to encourage and teach safe-sex practices and necessary health supplies, including methods of contraception, are vital to addressing long-term health issues with social causes. The sexual practices and the level of health education of the mother dictate the 
Ratio of under-five mortality rate for children from the poorest 20 per cent of households to children from the richest 20 per cent, $2000 / 2010$

Latin America \& the Caribbean

Southern Asia

Eastern Asia (excluding China) \& South-Eastern Asia

\section{3}

Northern Africa \& Western Asia

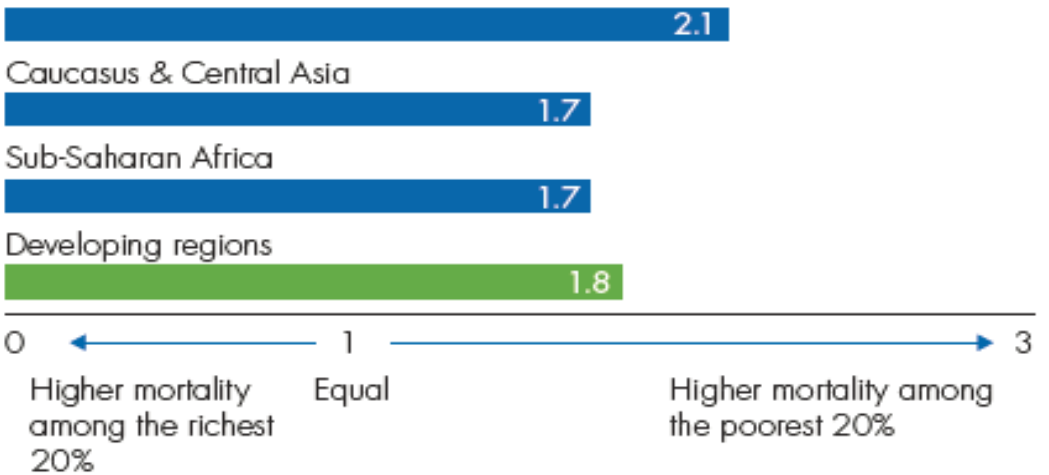

Figure 1. Ratio of under five mortality rate from children from the poorest 20 percent of households to children from the wealthiest 20 percent of households. ${ }^{29}$

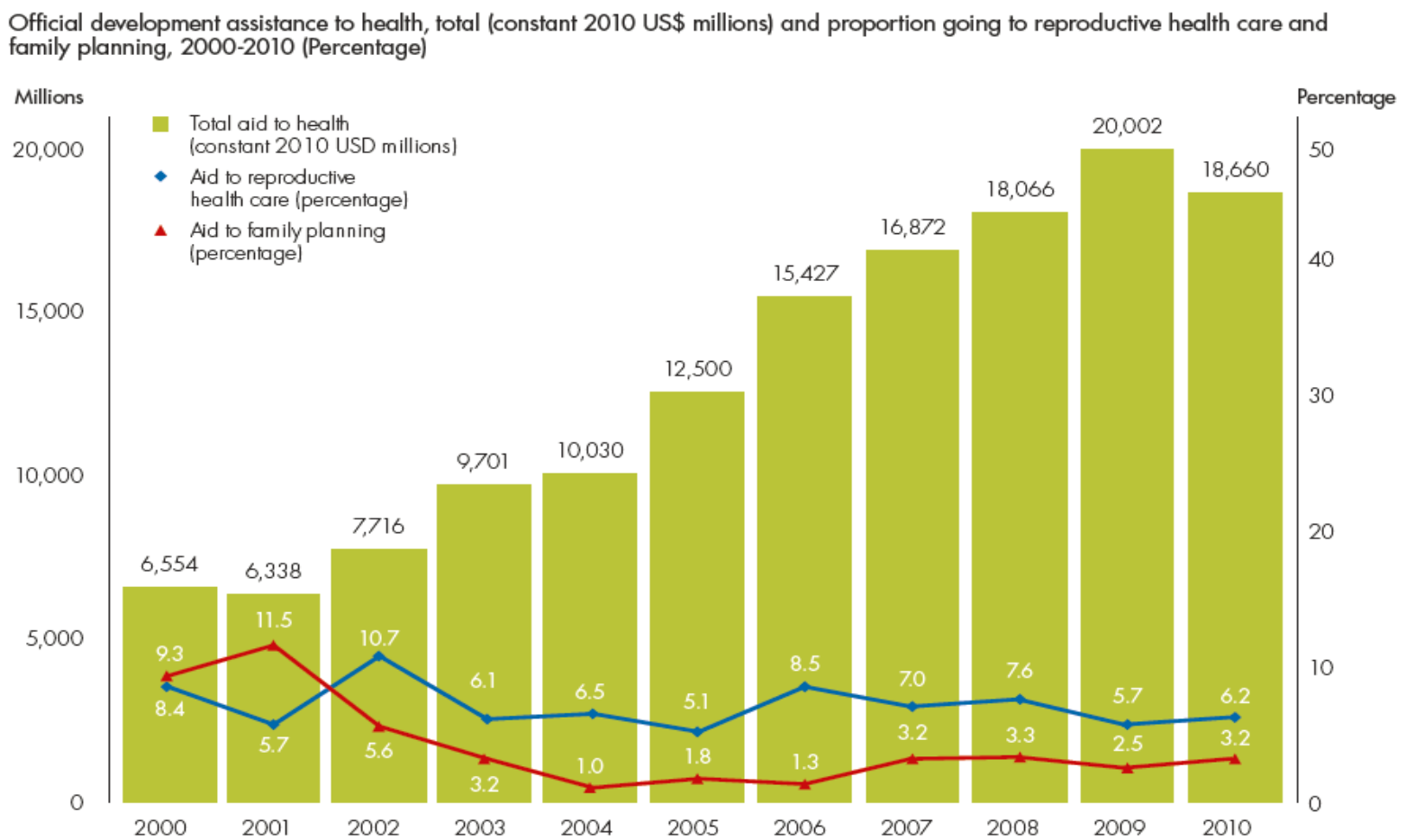

Figure 2. Aid to reproductive health care and family planning. ${ }^{29}$ 
number of children she will birth and her likelihood of contracting sexually transmitted diseases. These factors are central to predicting the overall health of her family. For example, more children in a family demands a higher income, which in turn affects the nutrition, education, and sanitation afforded by the family. The lack of funding currently allocated to reproductive care and family planning speaks to the importance of the social determinants of health perspective.

The five broadly accepted health determinants of a populations are summarized in Figure 3 , according to their estimated contribution to the population: genes, biology, and health behaviors collectively account for roughly 25 percent of population health while the social determinants of health, which includes the final three categories -- social environment, physical environment (total ecology), and medical care (health services) account for the other 75

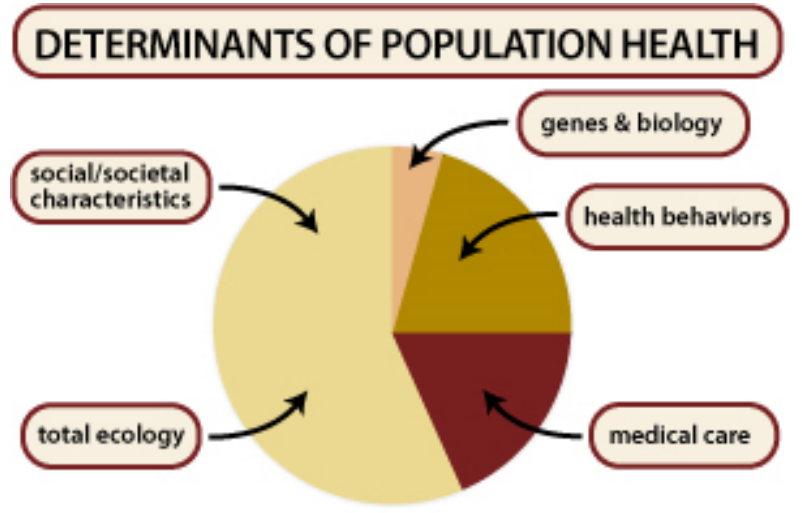

Figure 3. Determinants of Population Health.

percent. ${ }^{28}$ Because the social determinants of health are avoidable in nature, they should be receptive to improved policy choices and intensive action. This realization exposes negligence and inefficiencies in our current system. Prior policy choices, though well-intentioned, have not been able to navigate the plethora of obstacles facing countries in their missions to improve the health of their citizens.

\footnotetext{
${ }^{28}$ World Health Organization, "Commission of Social Determinants of Health Final Report 2008." http://whqlibdoc.who.int/publications/2008/9789241563703_eng.pdf.
} 
The evolving nature of global health with respect to the rates of incidence of noncommunicable diseases and the rising threats of environmentally based changes also provides evidence that a more social approach is the necessary option for the future.

\section{Rising Incidence of Non-communicable Diseases}

The transformation of worldwide disease burden from diseases that are communicable and able to be passed physically to those that are non-communicable demands a more comprehensive approach to healthcare. Non-communicable diseases, as defined by Dr. Kathryn Jacobsen, an epidemiologist and professor at George Mason University in the U.S, are diseases that are not contagious, such as cancers, endocrine disorders, neurological and psychiatric disorders, heart disease and other cardiovascular disorders, chronic respiratory diseases, digestive diseases, kidney diseases, and musculoskeletal and skin diseases. ${ }^{17}$ These diseases are caused by a variety of known and unknown factors. Known factors include genetic disorders, congenital abnormalities, general ageing processes, and autoimmune disorders. Many unknown factors also cause non-communicable diseases. The lack of progress being made in decreasing incidence levels of non-communicable diseases in populations in both developed and developing countries alike may be partially explained by these unknown factors that create gaps in knowledge.

The surging levels of non-communicable diseases in middle and high-income countries has managed to capture both the attention of media empires, such as the $B B C$ and the New York Times, and that of global-health epidemiologists and other health specialists. Perhaps somewhat surprisingly, reports have revealed that Sub-Saharan Africa remains the only region of the world that suffers from mortality rates of communicable diseases higher than mortality rates of 
noncommunicable diseases. ${ }^{29}$ After considering that of the 10 leading causes of death identified by the WHO in 2008, 6 were non-communicable diseases (see Table 3), this trend seems more realistic. $^{22}$

Unfortunately, non-communicable diseases are not among the health or development issues discussed in the 8 overarching MDGs or even included within the abstract authority of their 18 targets and have been principally neglected from the global-health policy agenda as a result. Their current international incidence levels speak for their need to be recognized as a policy priority for future global-health agendas. In the past few years, rhetoric of significant and influential global-health actors has increasingly presented cases explaining the potential future dangers accompanying unchallenged non-communicable disease rates. In 2011, the Centers for Disease Control and Prevention called non-communicable diseases a "public health emergency" and began to advocate for health-policy that would alleviate the effects of these diseases in specific states. ${ }^{30}$

Some academics contend that addressing the social causes that encourage the prevalence of non-communicable disease risk factors in populations is the needed approach of global-health actors. Four of the main non-communicable diseases, heart disease and stroke, cancer, diabetes, and chronic lung disease, all share fairly transparent and common risk factors: tobacco use, unhealthy diets, physical inactivity, intake of excessive amounts of alcohol, and high blood pressure and cholesterol. ${ }^{31}$ All of these risk factors stem from social causes; therefore, by prioritizing global-health policies that focus on social determinants, these prevalence of these risk factors in populations would be reduced. Investing more funding into programs provided by

\footnotetext{
${ }^{29}$ Bell, Ruth, Michael Marmot, and Sebastian Taylor, "Global Health Governance: Commission on the Social Determinants of Health and the Imperative for Change," Journal of Law, Medicine, and Ethics, 38(3): 2010

${ }^{30}$ Centers for Disease Control and Prevention, "The Problem of Non-Communicable Diseases and the CDC's Role in Combating Them," September 16, 2011. http://www.cdc.gov/globalhealth/ncd/overview.htm.
} 
the WHO Framework Convention on Tobacco Control, which provides support to those who want to stop smoking in addition to marketing educational resources that illustrate the negative effects of tobacco on the human body, is one example of a policy choice with roots in the social determinants of health perspective. Devoting aid to help institute economic policies in states that reduce levels of salt consumption, which would indirectly reduce the burden of high blood pressure, is another example of a socially-focused health policy. According to an article on global interventions that could prevent chronic, non-communicable diseases, reducing salt consumption by only 15 percent in populations in 23 selected low and middle-income states, could avoid 8 to 13 million deaths over the course of 10 years (from 2006 to 2015). Moreover, the cost of implementing this salt consumption reduction, in terms of human resources and policy needs, would be less than U.S. \$0-40 per person annually in low-income states. ${ }^{31}$

Non-communicable diseases should become a critical health issue on the forefront of most national and international policy agendas in coming years according to recent trends, and the social determinants of health approach is arguably both the most cost-effective and practical option for policy frameworks.

\section{Health Issues Created by Global Environmental Change}

Global environmental changes, reflecting growth in population sizes, continued energy use and consumption, and waste production, project major risks to human health in coming years, as increases in the Earth's surface temperature, at least for some time, if not permanently, give way to more thermal extremes and weather disasters, which include vector-borne, water-

\footnotetext{
${ }^{31}$ Asaria, P, D. Chisholm, C. Mathers, M. Ezzati, and R. Beagerhole, "Population-wide Interventions to Prevent Chronic Diseases," Lancet, 370: 2007.
} 
borne, and food-borne infections. ${ }^{32}$ Environmental change is the result of actions humans take that alter the natural world. These environmental changes, in turn, impact human health through interaction with the physical environment, which is encompassed as a category within the social determinants of health. Table 4 illustrates several human health effects of global environmental change and demonstrates the extent of integration between human health and seemingly

\begin{tabular}{|c|c|c|}
\hline Environmental Change: & Possible Pathways: & $\begin{array}{c}\text { Examples of Increased } \\
\text { Disease Incidence or } \\
\text { Prevalence: }\end{array}$ \\
\hline Ozone Depletion & $\begin{array}{l}\text { Increased exposure to } \\
\text { ultraviolet radiation }\end{array}$ & Skin cancer, cataracts \\
\hline Temperature Extremes & $\begin{array}{l}\text { Heat Waves } \\
\text { Increased geographic range } \\
\text { for insect vectors } \\
\text { Destruction of agricultural } \\
\text { products }\end{array}$ & $\begin{array}{l}\text { Heat stroke and death } \\
\text { Malaria and other vector- } \\
\text { borne diseases } \\
\text { Malnutrition }\end{array}$ \\
\hline Decreased Precipitation & $\begin{array}{l}\text { Increased Drought } \\
\text { Increased air pollution, } \\
\text { including spores, pollen, } \\
\text { smoke, and dust }\end{array}$ & $\begin{array}{l}\text { Malnutrition } \\
\text { Asthma, allergies, other } \\
\text { respiratory illnesses, and } \\
\text { meningitis caused by } \\
\text { Neisseria meningitides }\end{array}$ \\
\hline \multirow[t]{4}{*}{$\begin{array}{l}\text { Elevated Precipitation and } \\
\text { increased frequency of floods } \\
\text { and hurricanes }\end{array}$} & Flooding and rising sea level & $\begin{array}{l}\text { Drowning; cholera and other } \\
\text { diarrheal diseases caused by } \\
\text { contaminated water supplies }\end{array}$ \\
\hline & $\begin{array}{l}\text { Increased pools of standing } \\
\text { water for mosquito breeding }\end{array}$ & $\begin{array}{l}\text { Rift Valley fever, dengue } \\
\text { fever }\end{array}$ \\
\hline & Increased rodent population & $\begin{array}{l}\text { Hantavirus pulmonary } \\
\text { syndrome }\end{array}$ \\
\hline & $\begin{array}{l}\text { Destruction of agricultural } \\
\text { products }\end{array}$ & Malnutrition \\
\hline
\end{tabular}

Table 4. Human Health Effects of Global Environmental Change. ${ }^{33}$

unrelated environmental changes.

\footnotetext{
${ }^{32}$ McMichael AJ, Friel S, Nyong A, Corvalan C. Global environmental change and health: impacts, inequalities, and the health sector. BMJ 2008: 336: 191-94.

${ }^{33}$ UNEP, "Global Environmental Outlook Year Book 2004/2005: Emerging and Re-emerging Infectious Diseases: Links to Environmental Change."
} 
Sadly, studies of the Earth and the predicted environmental changes involving climate systems, food, freshwater, and currently vigorous ecosystems have shown that the future disturbances will "disproportionately affect the resource-poor and geographically vulnerable populations. ${ }^{34}$ The environmental changes will only serve to exacerbate the poverty and poor health standards of these regions, making it them even more critical to the global-health agenda.

Research indicates that environmental changes will not only affect the poor, undeveloped states at a higher rate than the developed, but also that they contribute to significant percentage of global disease burden, which only stands to increase. A WHO study recently concluded that 24 percent of "the global disease burden could be attributed to environmental factors. ${ }^{35}$ Table 5 summarizes the findings of this study by identifying the percent of cases attributable to the environment and then citing the specific environmental risk factors present for

\begin{tabular}{lcl}
\hline \multicolumn{1}{c}{ Disease: } & $\begin{array}{c}\text { \% of Cases Attributable to } \\
\text { the Environment: }\end{array}$ & $\begin{array}{c}\text { Primary Environmental Risk } \\
\text { Factor }>\mathbf{2 5 \%} \text { of cases } \\
\text { attributable to the risk factor): }\end{array}$ \\
\hline Intestinal nematode infections & $100 \%$ & Water, sanitation, and hygiene \\
Trachoma & $100 \%$ & Water, sanitation, and hygiene \\
Schistosomiasis & $100 \%$ & Water, sanitation, and hygiene \\
Japanese encephalitis & $95 \%$ & Water resources management \\
Dengue & $95 \%$ & Housing risks \\
Diarrheal diseases & $94 \%$ & Water, sanitation, and hygiene \\
Drowning & $72 \%$ & Recreational environment \\
Unintentional poisonings & $71 \%$ & Chemicals \\
\hline Lymphatic filariasis & $66 \%$ & Water, sanitation, and hygiene \\
Chagas disease & $56 \%$ & Housing risks \\
\hline Malnutrition & $50 \%$ & Water, sanitation, and hygiene \\
Lower respiratory infections & $42 \%$ & Indoor air pollution \\
\hline Malaria & $42 \%$ & Water resources management \\
Road traffic accidents & $40 \%$ & Land use and built environment \\
\hline
\end{tabular}

Table 5. Percent of Disease Attributable to Environmental Risk Factors. ${ }^{35}$

\footnotetext{
${ }^{34}$ McMichael Anthony, Jonathan Patz, and R Sari Kovats, "Impacts of Global Environmental Change on Future Health and Health Care in Tropical Countries," London School of Hygiene and Tropical Medicine, 54(2): 1998.

${ }^{35}$ Pruss-Ustun, A. and C. Corvalan, " Preventing Disease through Healthy Environments: Toward an Estimate of the Environmental Burden of Disease," World Health Organization, 2006.
} 
each disease. Sample environmental risk factors include water resources management, the recreational environment, chemicals, radiation, housing risks, and more.

As death rates continue to decrease and people live longer lives, urbanization persists, and lifestyle changes accompany advanced technology, the global environment will further transform. The ability to handle these environmental changes will depend on the widening perspective of health and the consideration of its social causes.

Global-Health Funding and Constraints Posed by Absorptive Capacity in Health Systems Overall, global-health funding has increased drastically over the past decade. The Institute for Health Metrics and Evaluation reported in 2009 that the development assistance for health (DAH) had quadrupled in amount as it jumped from an estimated U.S. \$5.6 billion in 1990 to U.S. $\$ 21.8$ billion in $2007 .^{36}$ This colossal international health budget, while having improved health-care as a whole worldwide, has not been able to fix as many critical health issues as anticipated. One example is the continuously rising number of undernourished people in the world. The UN Department of Social and Economic Affairs reported that 817 million people worldwide were identified as undernourished in 1990 and 1992 and acknowledged that the population had expanded to 830 million people in $2007 .^{37}$

Demands for increases in funding for global-health from developed nations have largely been met to date, but estimated projections for future health budgets indicate that the UN, WHO, and other international organizations will continue to request the same levels of funding

\footnotetext{
${ }^{36}$ Institute for Health Metrics and Evaluation, "Financing Global Health 2009: Tracking Development Assistance for Health." http://www.healthmetricsandevaluation.org/publications/policy-report.

37 Fakuda-Parr, Sakiko, "Should Global Goal Setting Continue, and how, in the Post-2015 Era?" UN Department of Economic and Social Affairs, 2012. http://www.un.org/esa/desa/papers/2012/wp117_2012.pdf.
} 
annually, if not more. Expectations that the G8 and other developed countries can and will continue to sustain these contributions are beginning to waver. ${ }^{38}$

Moreover, scholars have raised important concerns surrounding the potential negative effects brought on by absorptive capacity constraints in the health systems of many developing countries. The ability of a state to effectively administer and direct funding, while eluding political corruption, recruiting sufficient human resources, and reconstructing the health system's physical infrastructure is challenging in the most stable and fair political and economic environments. States ridden with political turmoil, caught in a violent war, or confronting overwhelming poverty face even more challenging circumstances. Attempting to implement health-policy directives with funding obtained from donor countries and agencies may easily overwhelm a health system and create adverse effects that not only prevent progress but also limit future donor investments.

Rwanda provides an example of a state that suffers from absorptive capacity constraints. The health system in Rwanda has been allocated U.S. \$187 million from 2003 to 2006 exclusively for HIV/AIDS initiatives from three international programs (the Global Fund, PEPFAR and the World Bank's Multi-Country AIDS Program), and the state's incidence of the disease has yet to move from the 2003 level of 3 percent of the population. ${ }^{39,40}$ The amount of aid invested into the state is astronomical. Factors that prevent Rwanda from addressing HIV/AIDS lie in the state's political and economic environment, or, in other words, are constraints associated with the national health system's absorptive capacity. Due to new performance-based

\footnotetext{
${ }^{38}$ WHO Bulletin. G8 urged to act on food crisis and health. http://www.who.int/bulletin/volumes/86/7/08020708/en/index.html

${ }^{39}$ Ministry of Health. Republic of Rwanda. Rwanda national health accounts 2003. Kigali: Ministry of Health; 2006.

${ }^{40}$ WHO Country Cooperation Strategy 2013 http://www.who.int/countryfocus/cooperation_strategy/ccs_rwa_en.pdf
} 
evaluation measures being implemented by some private health actors such as the Global Fund, failing to reduce the number infected with HIV/AIDS could cost Rwanda future aid packages.

The amount of money invested into a health system cannot predict the health of a people. Recent trends in states' annual health-expenditures support this assumption. Despite the fact that the U.S. government spends 25 times more per capita per person on health-care than Cuba, the U.S. only manages to rank 27th in the world in life expectancy, which is only one rank higher than Cuba's current standing of 28th in the world. The U.S. average life expectancy in 2000 stood at 77 years, and the government spent an average of $\$ 4,500$ per person. In contrast, the average life expectancy of a person in Cuba in 2000 was 76.9 years, and the government only spent \$186 per person. In other words, the average Cuban lives only 0.1 years or a month and a half less than a person in the U.S, while the government exhausts a mere $1 / 25$ of the per capita

\section{The Cost of a Long Life}

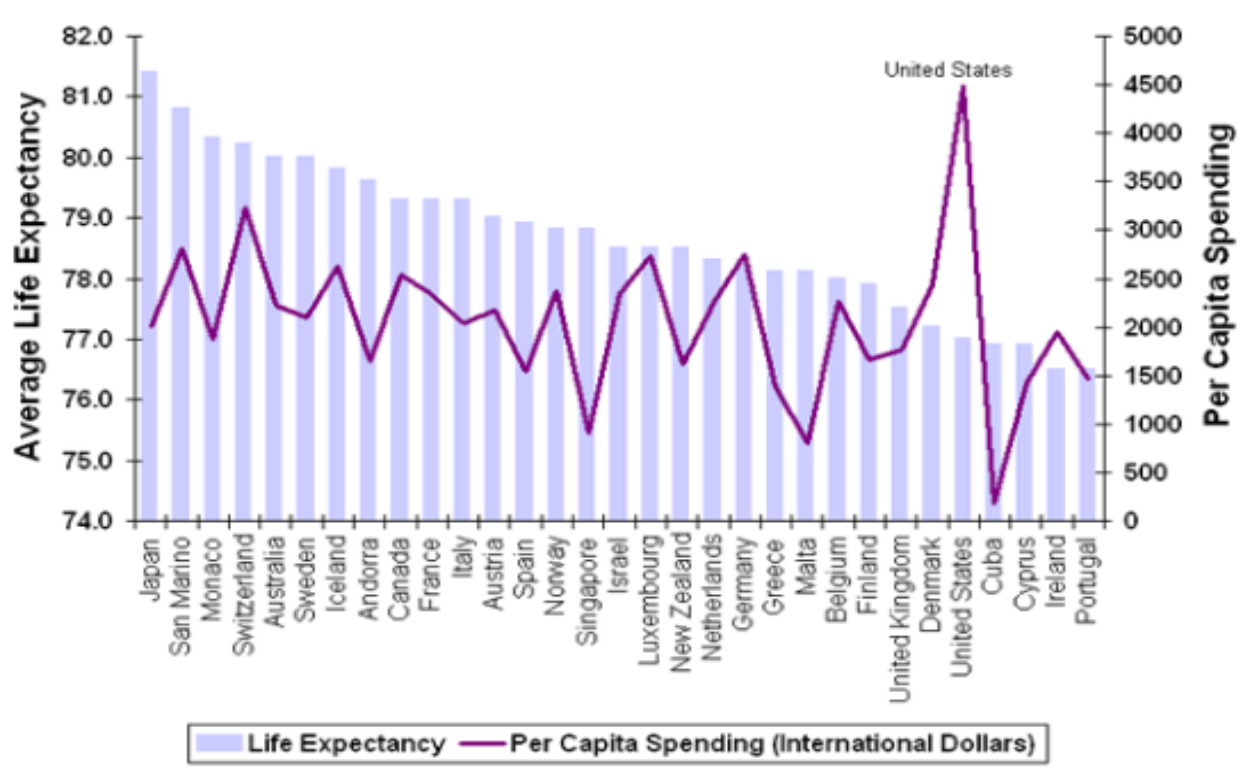

Figure 4. Per Capita Health Care Expenditure and Average Life Expectancy of Selected States in $2000 .{ }^{41}$

\footnotetext{
${ }^{41}$ UC Atlas of Global Inequality, "Health Care Spending: Large Differences, Unequal Results," 2000. http://ucatlas.ucsc.edu/spend.php
} 
cost. ${ }^{31}$ Of course, the U.S. is an extreme example, as its health-care expenditure far surpasses every other state's in the world. Yet, the data summarized in Figure 4 clearly demonstrates that simply pouring money into health systems does not ensure success. This is further supported by estimates that allot $\$ 40$ to $\$ 75$ million annually for the maintenance of the Millennium Development Goals. ${ }^{25}$ Even with the overwhelming funding being channeled through the UN for programming and initiatives created to ensure the achievement of the MDGs, the funding has not been enough to ensure the delivery of the 18 targets (see Table 1).

These statistics allude to a clear problem in global-health funding distribution and allocation. The amount of funding a particular state and donor states or agencies invest in its health system are not producing positive enough results to warrant such drastically high aid investments. Changing the method of investment is the next logical step. The social determinants of health perspective provides a framework for policy choices that will redirect funding channels toward sources of long-lasting change, such as improving and increasing resources for health education in primary and secondary schools and economic policy that supports health affordability and accessibility, thereby increasing the absorptive capacities of these health systems in developing states.

\section{WHO Commission on the Social Determinants of Health}

As the research has demonstrated, the disease-specific programs of the past revealed significant problems in health that range from inadequacies stemming from the poor quality of health systems, the imperative connections between political leadership and economic policy, and the fragmentation and replication of resources in the implementation of global-health policy. Literature currently published at the international level as a result of conferences among world 
leaders and scholars warrants collective action through health-care initiatives for more long-term, measurable results. These intentions may only be guaranteed through a change in perspective and a shift away from the disease-specific, vertical approach. After all, the distribution of mosquito nets among children in a rural village does not influence the likelihood that they will receive primary or secondary education and grow into young adults that are capable of providing the income needed to obtain housing and sanitation technology that discourages the spread of malaria or HIV/AIDS. Moreover, a mother's life, saved during childbirth, may not be protected from cervical or breast cancer as she reaches middle and old age.

The realities brought upon us by the rising burden of noncommunicable diseases and global environmental changes demand more integration and intention in policy. This realization along with the popularity and acceptance of the social determinants of health perspective led to the creation of the Commission of Social Determinants of Health (CSDH). The Commission, created in 2007 to provide recommendations and analysis on the potential of the social determinants theory, operates independently of the WHO yet persists as an initiative stemming from and reporting to WHO instruction. The main contributions of the CSDH include improving daily living conditions in which people are born, grow, live, work and age; tackling the inequitable distribution of power, money and resources-- the structural drivers of daily living conditions --globally, nationally, and locally; and measuring and understanding the problem of health inequities and assessing impact of action. The Commission espouses the opinion that many sectors combine to influence health outcomes; therefore, it is the collective responsibility of each sector to institute change. ${ }^{30}$ This view reflects other international statements, such as the Oslo Ministerial Declaration and the Accra Agenda for Action, in that it states that countries both extending and receiving aid must collaborate to achieve effective health programs and policy and 
therefore improvements in health. Moreover, it asserts that all sectors of governments, including economic, social, and political divisions, contribute to shaping health. The Commission further identified entry at existing systemic inequities, which are summarized in Figure 5.

The Commission also assembled five collective recommendations to the WHO. First, it argued that the WHO be given more jurisdiction in the development of health policy and a greater voice in representing health in global governance. Second, it called for more participation and voice for the people in health policy. Third, the CSDH called upon WHO to integrate the social determinants of global health as the guiding principle for all WHO programs and departments. Fourth, it argued that global patterns of trade had tremendous influence on the

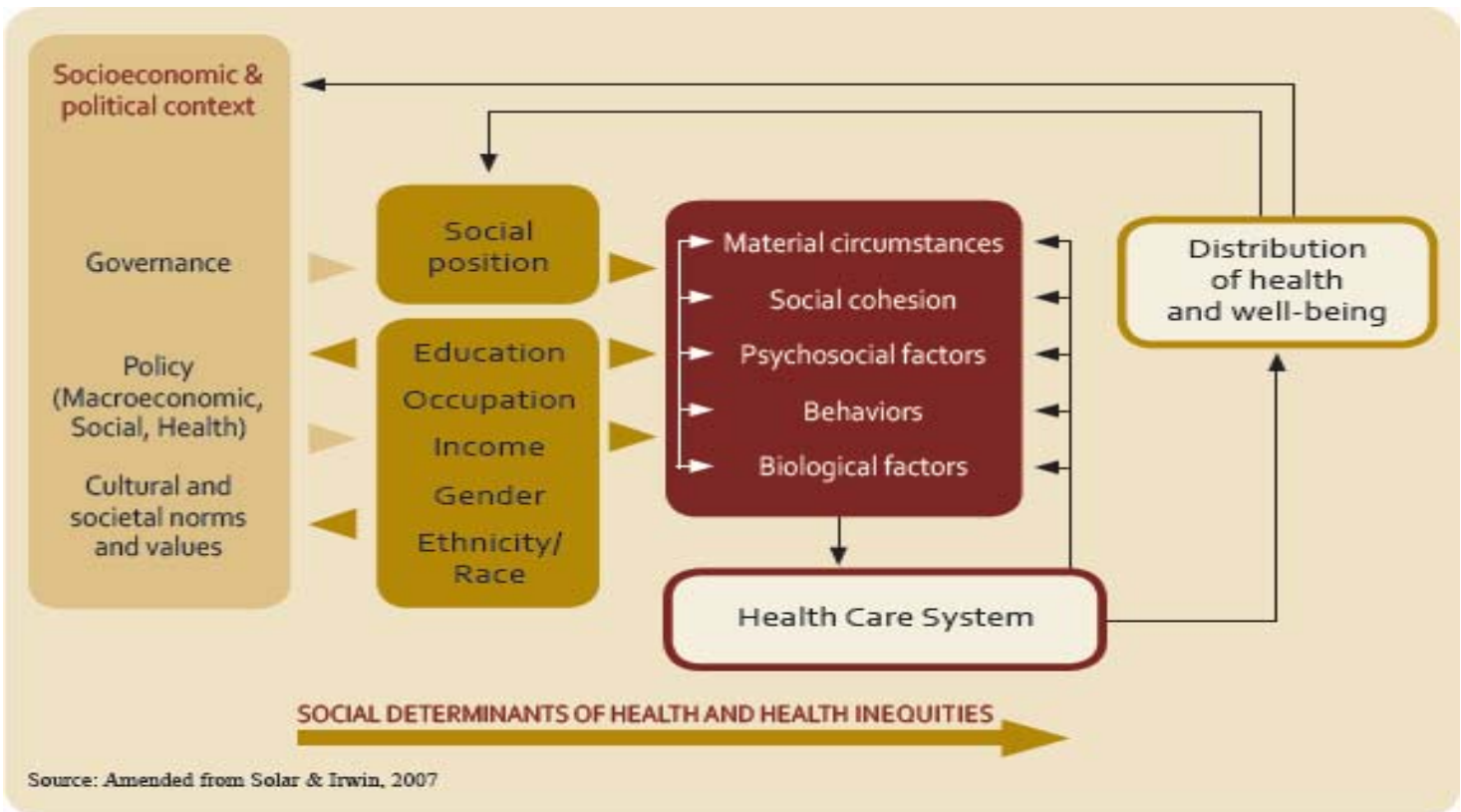

Figure 5. CSDH Conceptual Framework and Entry Points for Intervention ${ }^{30}$

social determinants of health, which also stood as an underlying argument for health to be given greater priority in global governance. Finally, CSDH demanded a firm commitment of donor countries to honor previous promises of aid to low-income, developing nations and to further increase aid donations. 
The CSDH report was the first official statement released by a group of stakeholders officiated by the WHO that called for a more transparent voice for health in global governance. The CSDH view that the WHO needed a more defined role in international health policy-making and prioritizing is completely justified. WHO's current administrative counterparts, which include UNAIDS, the Roll Back Malaria Initiative, and other UN specialized agencies such as, the Food and Agricultural Organization (FAO), the United Nations Children's Fund (UNICEF), and the United Nations Development Programme (UNDP), all generate their own programming, their own agenda, and their own data. This overwhelmingly complicates the public international health system. No clear hierarchy identifies the actor responsible for collecting the entirety of the health data. As a result, collecting comprehensive data from all UN associated organizations is almost impossible. The fragmentation of agencies and duplication of efforts within the public sector is one of the main obstacles of the WHO and has contributed to the transfer of donor aid to private organizations.

Whether or not leaders in the WHO and in the UN take these reforms and recommendations of the Commission seriously remains to be seen. The current focus is still on ensuring the success of the MDGs by securing the necessary needs and funding for the existing programs responsible for attaining this mission.

\section{Part II: Conflicts Extending from Sociopolitical Global Health Frameworks}

\section{Many Frames of Global Public Health}

With respect to health promotion, global-health is presented in several frameworks, which vary according to the level of study: local, national, or international. These frameworks or perspectives on global health form the basis of arguments for funding proposals and policy 
choices. While the concept of the social determinants of health, as supported by the analysis provided by the Commission of Social Determinants of Health, has been accepted by health authorities in most regions across the world, the international statements intended for the ascertainment of grants and aid must be presented according to a persuasive framework that promotes a rationale asserting foreign-policy responsibilities. This discourse supports and conveys a general rhetoric for the construction and comprehension of global-health needs. Consequently, this rhetoric determines international expectations and individual state's obligations and commitments. The three most frequently used frameworks utilized in these statements are as follows: (1) health as a matter of security; (2) health in the context of development; and (3) health as a human right. Through analysis, these three frameworks help to explain current conflicts faced in achieving global health goals.

\section{Health as a Matter of Security}

The first and most dominant form of discourse encompasses the framework of health as a matter of national and international security. This framework reflects the assumption that nationstates consistently invoke an explicit responsibility to "protect their citizens from foreign risk by guarding their borders, whether the 'invaders' are pathogens or people". ${ }^{42}$ As noted by a report on U.S. National Security and Global Health issued by the U.S. Department of Defense, "the health of human and animal populations overseas can affect nearly every aspect of Americans’ safety and prosperity_-from trade to the stability of foreign governments and populations, to the physical well-being of U.S. citizens at home." ${ }^{43}$ This framework was increasingly justified

\footnotetext{
${ }^{42}$ Labonte, Ronald, "Global Health in Public Policy: Finding the Right Frame?" Critical Public Health, 18(4): 2008.

${ }^{43}$ CSIS Global Health Policy Center, "U.S. National Security and Global Health: An Analysis of Global Health Engagement by the U.S. Department of Defense," 2009 http://csis.org/files/publication/090421_Bonventre_USNationalSecurity_Rev.pdf.
} 
following the anthrax mailings of 2001, documented as the first major bioterrorist incident in American history, in which envelopes containing several teaspoons of anthrax-contaminated powder were dropped into a mailbox in New Jersey. The envelopes led to the eventual death of five people and sickened 17 other U.S. citizens. This incidentally also briefly crippled the entire U.S. mail-service system and forced the evacuation of numerous federal buildings in Washington, D.C. ${ }^{44}$

The use of health and the transmission of disease as a weapon in biological warfare traces its roots back to the era of colonialism in the New World by Francisco Pizzarro in South America and during the French and Indian War. In the case of the latter, Sir Jeffrey Amherst attempted to gain an advantage over the French in the French and Indian War and ordered his soldiers to recover blankets from infantrymen stricken with smallpox; he later arranged the sale of the disease-ridden articles to Native American groups that had aligned themselves with the French, and to his benefit, achieved disaster. Years passed and healthcare technology advanced, as did the capacity of inter-state biological threats, evidenced by the brinksmanship between the Soviet Union and U.S. in the Cold War era. ${ }^{45}$

Modern day SARS, avian flu, and swine-flu epidemics have served to raise political clout in well-developed countries for increased action in global health measures. These epidemics have also fostered an exaggerated sense of fear that corresponds with an a distortion in global health risk and an agenda that strays toward the repercussion of the war on terror.

The increasing securitization of health has disproportionately encouraged funding to be directed toward issues that are designated as health risks by political assessments: HIV, as the most applicable example for expenditures of the World Health Organization and other health-

\footnotetext{
44 The New York Times Anthrax. http://topics.nytimes.com/top/reference/timestopics/subjects/a/anthrax/index.html. ${ }^{45}$ Phillips, Michael B, "Bioterrorism: A Brief History," Department of Internal Medicine, Mayo Clinic. http://www.dcmsonline.org/jax-medicine/2005journals/bioterrorism/bioterrorism_history.pdf.
} 
related organizations, and the avian flu, the most recently publicized feared pandemic. In actuality, global risk is not taken into consideration as the incidence rate and death toll from the neglected tropical diseases, from childhood and maternal illnesses, and from the chronic noncommunicable diseases such as cardiovascular disease and respiratory infection, is much higher than that of HIV and the avian flu combined.

In addition, the practice of framing health concerns as national security concerns disregards many prominent global-health issues in favor of terrorism and the manifestation of bioterrorism as an elicit component of warfare. The United Nations Economic and Security Council and the Commission of Human Rights, in regard to this issue, have stated that this practice supports a definition of national security that is... "essentially militaristic and...retrogressive.... with reliance placed on the superiority of military firepower and the curtailment of civil liberties'." ${ }^{46}$ In other words, because of heightened publicity of nationalsecurity interests among Western governments, such as the U.S, labeling health issues according to their potential to create widespread panic and fear of infection is damaging, as these fears may morph into fears of bioterrorism and, by extension, terrorism itself.

In this argument, identifying health issues with such close reference to terrorism promotes the development of a more militaristic perspective of patrolling health services. Yet, the view of health as a matter of security remains the most effective method of garnering funds from developed donor nations and dominates the mentality of principle Western donor nations in their categorization of global health initiatives as necessity and responsibility. Furthermore, this explains the large sums of promised aid that has yet to be delivered as well as the generosity or lack thereof among the world's leading economies. As their dominant global-health framework

\footnotetext{
${ }^{46}$ UN Economic and Social Council, "Globalization and its Impact on the Full Enjoyment of Human Rights." 2003.
} 
dictates, only global-health issues that are national security threats deserve priority in policy and funding directives.

\section{Health in the Context of Development}

The relationship between health and development has changed considerably over the years. Originally, development was seen as a means of establishing gains in health; in other words, increased development brought improved health to a population. Recent research has asserted that health is, in fact, an engine of economic growth itself; therefore, economic gains accompany health improvement initiatives. This framework has been particularly compelling for political reasons, as the discipline of international health promotion has long attempted to prove its merit by monetizing the results of its efforts. Subsequently, aid for global-health initiatives has largely existed in the form of capital transfer from developed to developing countries.

Despite the heavy influx of capital by donor countries, recipients of aid have in many ways failed to develop their health systems and by extension, their economies to the standards envisioned by donors. Understandably, this framework has received much criticism. In some cases, the majority of capital aid awarded to a state has been discovered to be lost before reaching its intended destination because of corrupt governmental practices, profit repatriation, and the recycling of aid back to donor countries as a result of purchases of their goods and services. ${ }^{38}$

Moreover, the fact that donor countries will use promises of aid and dictate their funding allotments to needy states based on that particular state's perceived possible economic gain is detrimental to the goal to improve global health overall, as donations of aid become highly concentrated in specific regions that host highly lucrative resources or entertain political influence. This trend is unavoidable when funding comes from a public source and is a possible 
argument for the relatively less biased private sector. Furthermore, the trend is natural of the capitalistic, market-approach economic model but injurious to the objectives of global health. For example, more than 60 percent of aid increases were awarded to Afghanistan, Iraq, Nigeria, and the Democratic Republic of Congo between the years of 2001 and 2001-- the former three house some of the world's largest oil deposits and the latter is home to extensive mines containing several expensive minerals. Despite such huge inflows of aid, these countries impoverished populations equal to only 3 percent of the world's. ${ }^{47}$ China provides another example. Recently, China brokered a deal with Costa Rica to guarantee international political recognition in its diplomatic battle with Taiwan. In exchange for Costa Rica's shift in diplomatic recognition of Taiwan in favor of the People's Republic of China, the Chinese government offered to buy $\$ 300$ million of Costa Rican bonds, grant \$130 million in aid for development, and provide scholarships to enable students to study in China. ${ }^{48}$

Moreover, much of the aid that is disbursed is actively used to pay back domestic creditors and foreign debts, which is, in many cases, owed to the donor country. In effect, reported aid statistics are not accounts of the aid that actually reaches the health systems and the people; they are only indicative of the aid that is promised by donors, making many aid reports misleading.

Furthermore, this framework of health in the context of development results in the distribution of health funding in vertical disease-based initiatives. These vertical disease-based initiatives many times have short-term projections that enable simple but numerous data collection to validate achievements and progress. Social determinants of health, a more

\footnotetext{
${ }^{47}$ World Bank, "Strengthening Mutual Accountability, Aid, Trade, and Governance." 2006. http://www.imf.org/external/pubs/ft/gmr/2006/eng/gmr.pdf.

${ }^{48}$ Bowley, Graham, "Cash Helped Win Costa Rica's Recognition," The New York Times, 2008. http://www.nytimes.com/2008/09/13/world/asia/13costa.html.
} 
horizontal approach, does not yield data in such technical, explicit terms nor with such ease of collection. Therefore, to some extent, proponents of the health in the context of development discourse have only be able to argue effectively for funding and policies that supports vertical disease-based initiatives, which explains the prevalence of the disease focused health MDGs.

Yet another flaw that corresponds to this framework is the disproportionate benefits it awards to countries that pursue neo-liberal economic ideology and market liberalization efforts as compared to those countries who choose to pursue other economic models. Donors have been markedly more interested in funding endeavors in states that offer more globally integrated economies. This flaw too is inherent in the realm of foreign investment, as states only want to invest their funding into reliable economies and less corrupt political institutions. These reliable economies tend to be those that are more capitalistic and market-based.

Overall, the discourse of this framework, health in the context of development, limits the range of instruments and actors that participate in global-health initiatives as it chiefly biases access to global health initiatives according to the international economic interests of donor countries, which are comprised of mostly Western, capitalistic economies. Aid disbursements and support must serve the political interests of the donor agency or state, and a therefore inevitable in this framework.

\section{Health as a Human Right}

The Universal Declaration of Human Rights, adopted unanimously in 1948 by the UN, lists health as one of many basic human rights. Human rights provide an overlying covenant of governmental responsibilities; they are universal in that they should be and are available to everyone, and they are irrevocable. The Universal Declaration of Human Rights specifically 
states in Article 25 that "everyone has the right to a standard of living adequate for the health and well-being of himself and his family, including food, clothing, housing, and medical care and necessary social services, and the right to security in the event of unemployment, sickness, disability, widowhood, old age, or other lack of livelihood in circumstances beyond his control." ${ }^{49}$

Human rights reign as the most globalized political value of the modern era, as determined by the countless international statements, doctrines, conferences, commissions, and reports generated on their reality and progress, or in some cases neglect; health is a focal point included in all of the mentioned doctrine, typically stated in terms of "the right to the highest attainable standard of physical and mental health." ${ }^{38} \mathrm{UN}$ international doctrine stipulates an expectation that all countries provide human rights for their citizens, and their annual performance is reviewed by the United Nations Human Rights Committee.

Another aspect of the health as a human right's framework was introduced in 2000 by the United Nations Committee on Economic, Social, and Cultural Rights in a mandate that governmental responsibilities in relation to health as a human right extended beyond domestic borders to include the international sphere. Because health-care is viewed as a human right, it was ruled a violation of human rights when international or national actions were taken that thwarted a person's access to healthcare services or technology. The Committee affirmed that it was necessary for state actors to respect the right to health-care in other countries, by both evading participation in international agreements that would impact the health of peoples negatively and preventing the institution of contracts or other infringements drafted by third-

\footnotetext{
${ }^{49}$ Universal Declaration of Human Rights. United Nations. http://www.un.org/en/documents/udhr/index.shtml\#a25
} 
party actors such as corporations through political means. ${ }^{50}$ This statute included provisions which entailed obligations of prosperous states to intervene in developing states where progress toward achieving human rights of health-care by providing assistance and counsel.

In this framework, each person must have access to healthcare despite their economic situation, political affiliation, location of residence, or cultural background. This raises serious questions about the distribution of healthcare in and among countries. Who is in charge of the distribution of health services and technology? Which is the party responsible for the payment of these services?

In addition, ethical considerations are brought forward. Is it justifiable to perform a surgery that costs millions on someone who is older or should the same advanced technology rescue the life of a newborn? Should resources be allocated toward single parents and their children or traditional families? Furthermore, should priorities be given to the strong and healthy, and therefore more likely to survive, or the injured and weak? Paul Farmer, a highly published physician and founder of the non-governmental organization Partners in Health, alluded to disparities in terms of resources and choice.

The ethical dilemmas that are the primary focus of conversations in the literature or on hospital rounds are often about an embarrassment of riches. Making choices that involve options. How long should we continue life support? What constitutes brain death? Should we perform liver transplants for people who are alcoholics? Of course these are serious problems for families facing grave decisions for their loved ones. But in Haiti and in

\footnotetext{
${ }^{50}$ United Nations Committee on Economic, Social, and Cultural Rights, "Twenty-five questions and answers on health and human rights," Health and Human Rights Publication Series of The World Health Organization, 2000.
} 
other similar places it's about no options, about lack of access to just the basics: vaccines, clean water, food, and treatment for tuberculosis or AIDS. ${ }^{51}$

Health situations and issues are completely different among neighboring states, let alone states half around the globe; consequently, what constitutes access to healthcare services and technology cannot be quantified. To mediate this obstacle, the United Nations developed four overarching criteria to evaluate healthcare access, as summarized in Figure 6. Critics have argued that these criteria are idealized guidelines that can never be realized.

Flaws in this framework, in addition to the health questions raised surrounding the ambiguity of health accessibility and availability, correspond to the lack of enforcement measures inherent throughout its ideology. No mechanism of enforcement has been instated so that states that do not preserve the integrity of human rights are subject to consequences. The only consequence to date is international shaming through negative publicity

\section{Figure 6. Criteria to Evaluate Access to Health. ${ }^{47}$}

1. Availability: An adequate number of functioning, staffed, and stocked medical and public health facilities exist.

2. Accessibility: Health care services and information are easily accessible and economically affordable. No discrimination against people because of their sex, age, marital status, or any other physical or cultural characteristic occurs.

3. Acceptability: Ethical standards of health and medicine are in practice. These standards respect cultural and gender differences and life-cycle requirements. All patients and peoples are treated with the appropriate dignity.

4. Quality: All health facilities, and goods and services are of good quality and scientifically and medically adequate.

and other castigatory pronouncements.

\footnotetext{
${ }^{51}$ Paul Farmer in an interview with Patricia Cohen for The New York Times, 29 March 2003. http://www.nytimes.com/2003/03/29/arts/q-a-health-care-for-the-poorest-as-a-central-humanright.html?n=Top/Reference/Times Topics/Subjects/T/Third World and Developing Countries
} 
Other flaws are evident in much of the rhetoric that shaped the 'health as a human right' framework. Much of the rhetoric cannot be truly instituted because it is not reasonable. For example, some poor states are unable to provide their people with enough food, let alone medical coverage. Along these lines, access to health-care may be argued to be a need instead of a right.

The health as a human right framework, while principally utilized by the UN and international organizations in current times, does not and will not always have the persuasive elements provided by the other two frameworks discussed above. To make health as a human right a more effective framework, standards and penalties must be enacted in international law, with specific guidelines for those states who neglect their peoples or a detailed list of exceptions for states that cannot provide rights in general.

\section{Conclusions:}

Creating a global-health policy agenda, international standards, and benchmarks for the post-2015 era is imperative for continuous growth and progress in health and development. In order for the social determinants of health perspective to improving global health, the most widely-endorsed approach by scholars and international organizations alike, to be implemented, the frameworks that categorize health as a matter of security, in the context of development, and as a human right must be addressed. I propose three policy choices to help mediate the implementation of the social determinants approach in the post-MDG 2015 era. First, the recipients of aid should take on more responsibility in requesting and planning for the execution of funding in their respective health systems. Second, the evaluation and performance standards of private sector organizations should be used as a model for public sector organizations. Third, a 
body completely separate from the WHO should be established to produce all forms of globalhealth policy analyses and progress reports for all public sector organizations.

\section{Assigning Recipients of Aid More Responsibility}

Because of the arguable bias in effort of wealthier donor states compared to that of the recipients states, the global-health public sector should assign more responsibility to recipient states, and therefore ensure increased local, national, and regional participation in the state that is receives funding. There are several reasons for this proposal. First, the horizontal approach encouraged by the social determinants of health perspective where policies from all sectors, such as economic, political, and environmental, impact health system outcomes, requires much cooperation from the recipient state. In order for this social perspective to achieve results, health should clearly be a political priority of the government of the recipient state. The shared responsibilities defined in the Monterrey Consensus, the Paris Declaration for Aid Effectiveness, and the Accra Agenda for Action should be reviewed and upheld through this enhanced participation of recipient states. Second, donor agencies and states will be more apt to continue aid levels if effective results are attained. Introducing health-care policies that are approved and designed with the help of the recipient state helps to ensure effectivity.

Moreover, even if a recipient state is unable to contribute monetarily to the health system, the state is committing to the legitimacy of the policy and is an advocate for its success. Resources should meet commitment from all parties in one form or another. For example, Canada and the U.S. carried through on the majority of their promises of aid as each state achieved 107 of 111 percent of aid commitments to states in Africa as of 2009. On the other hand, African leaders' promises of devoting 15 percent of their budgets to health in 2001, have 
not been realized. As of 2010, only 6 percent of these African states have met the target. If wealthier donor states, such as the U.S. and Canada, are expected to continue providing aid, African states should be held accountable as well, even if their terms of agreement must be renegotiated to more realistic levels.

Above all, increased participation from local recipients of aid, such as villages or communities, would encourage more confidence in existing health systems, in the persons delivering health messages, and in the benefits of receiving medical treatment and therefore increase the prevalence among people. This can also be considered as an economic argument for increased "consumer confidence" of health as a service and good.

\section{Evaluation Methods and Performance Standards Utilized by the Private Sector}

Evaluation and performance standards should be increasingly borrowed from the private sector, as these donor organizations charge recipients of aid with much accountability. The private sector has achieved more significant results with health initiatives in developing states than the public sector, and generally boast more integrated, responsible partnerships. For example, the Global Fund to Fight Malaria, HIV/AIDS, and Tuberculosis recently revoked its grants for health in Uganda and Chad due to ill usage and poor administration of the funds. The Global Fund delineates clear evaluation standards and results-based reporting, a scenario that promotes a track record of good stewardship and performance by demanding less reports and data collection requirements from states with a history of reliable, positive records. In other words, states that administrate funding as stipulated by the Fund's guidelines and honor their aid grant agreement are rewarded with more trust and less monitoring. Implemented by the public sector, this model would equivocate access to aid resources with consistently improving results 
and reporting from recipient states. While it may be impossible to implement the same system within the public sector, incentivized performance of some type would be effective.

Above all, the current costs of global-health policy directives are not sustainable. Continuously raising the costs of implementation is not a mandate for donor states to increase funding. Rather, it is a request. The global economic recession of recent years will only lessen the capacity and willingness for donor states to increase funding levels.

Therefore, utilizing scarce funds that are undoubtedly being wasted by recipient states is inefficient and illogical, especially when new perspectives, such as the social determinants of health perspective, demand full cooperation and honesty from all parties. Regulation and enforcement must be enacted by the public sector.

Assuredly, while the public sector cannot completely cannot withdraw all forms of development and health assistance to states, they can remove significant contributions. Those states at war or those enduring exceptional political tumult or economic hardships could still receive levels of assistance. Yet, the institution of the social determinants of health perspective requires a stable sociopolitical and economic environment. As a result, developing different health funding packages to specific states that meet certain criteria might be a solution. A tiered system in which different programming efforts were implemented in various countries would ensure that the aid and human capital costs of investing in the social determinants approach would not be dissipated frivolously.

Moreover, an effective social determinants of health approach necessitates increased investment of human capital in contrast to the past and current trend of contributing monetary aid. Expertise from trained and educated health administrative personnel would better the new social approach to health by contributing ideas for improved policy, providing training to health 
system staff in the recipient state, and a first person perspective and surveillance of performance of both the donor agency or state and the recipient.

\section{New Approach to Technical Support Operations within Global-Health}

Unarguably, WHO need not be implementing policies and also evaluate the success and progress through collection and analysis of its own data. A different or new administrative body should be charged with the responsibility of evaluating data from global-health policy and reporting on that same data. There is a technical and ethical need for different sectors: one sector for implementation and financing of health-policy, one sector for evaluation and analysis, and one sector for enforcement of standards. This would not only necessitate increased coordination among different public sector actors, but also perhaps even among private sector actors. A central administrative organization that is the sole provider of data reporting and technical evaluation would be beneficial in terms of legitimizing results of specific health initiatives.

States would be more independent and have more ownership over their health systems and the ways in which funding is spent. Potential influence from an organization that grants the funding and also provides technical support and a biased preference for policy management would be eliminated. More ownership over their respective health systems also encourages the first proposed policy choice, which calls for increased responsibility and participation of recipients of aid.

With a more reliable and consistent system to evaluate and analyze effectiveness of health-policy from different actors, the social determinants of health would be much more likely to achieve positive results. With three or more bilateral and multilateral organizations operating within the same locale, it becomes difficult to isolate both successes and failures of specific policies and analyze health outcomes. Because the social determinants of health approach is an 
aggregate compilation of policy measures in sectors beyond those specifically relating to health, this proposed administrative could pinpoint critical problem areas and help to direct future policies towards those that have proven themselves successful. 